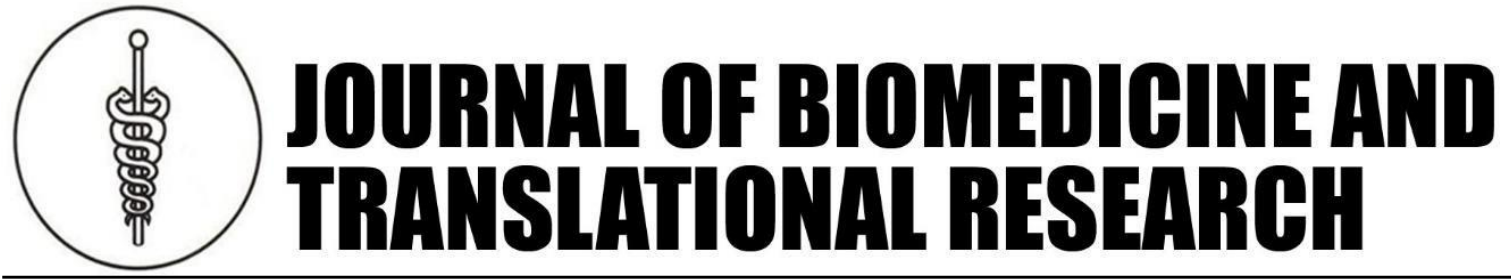

Copyright (C2019 by Faculty of Medicine Diponegoro University and Indonesian Medical Association, Central Java Region

Research Articles

\title{
Antioxidant Herbs Supplementation Inhibits Endometriosis Extension in Mice
}

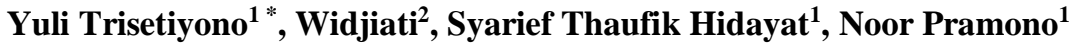 \\ ${ }^{1}$ Department of Obstetrics and Gynecology, Faculty of Medicine, Diponegoro University, Indonesia \\ ${ }^{2}$ Department of Embryology, Faculty of Veterinary Medicine, Airlangga University, Indonesia
}

Article Info
History
Received : 24 April 2019
Accepted : 15 Oct 2019
Available : 31 Dec 2019

INTRODUCTION

Endometriosis is a common gynaecological disease which is characterised by the growth of endometrial tissue outside the womb cavity. Endometriosis is closely related to chronic pelvic pain and female infertility. ${ }^{1}$ The pathogenesis of endometriosis remains unclear and involves multifactorial etiologies. Increased oxidative stress (OS) is known to be associated with this disease.

Keywords:

\begin{abstract}
Background: Increased oxidative stress causes inflammation and increases angiogenesis. It presumed to promote the proliferation of endometriosis tissue. Kebar grass (Biophytum petersianum) and other herbs such as green tea and Cucumis melo, which contain high antioxidants, are expected to decrease oxidative stress, inflammation, angiogenesis, and reduced endometriosis implants.
\end{abstract}

Objective: To investigate the effects of Kebar grass, green tea, and Cucumis melo to malondialdehyde serum, tumor necrosis factor alpha, and vascular endothelial growth factor expression, and the area of the endometriotic implants.

Methods: Twenty-eight mice were divided into four groups, i.e., the first group of endometriosis mice was given Kebar grass extract; the second group was assigned green tea extract, the third group was given the combination of Cucumis melo extractgliadin, and the last containing the untreated endometriosis mice as the control. Each treatment was given for 14 days. The data of MDA serum level, the area of the endometriotic implants, TNF- $\alpha$, and VEGF expression were collected and analyzed.

Results: The MDA serum levels of the groups treated with Kebar grass extract, green tea extract, and Cucumis melo extract - gliadin were significantly lower $(\mathrm{p}=0.001)$ than the control group. TNF- $\alpha$ expression of the groups provided with each treatment also lower than the control groups $(\mathrm{p}=0.002)$. However, only the administration of the Cucumis melo extract-gliadin resulted in lower VEGF expression compare with the control ( $\mathrm{p}=0.017$ ). Finally, the area of the endometriotic implants of the mice models administered with each treatment was smaller than the control group $(\mathrm{p}=0.003)$.

Conclusion: Kebar grass as well as green tea and Cucumis melo-gliadin inhibits endometriotic implants extension by decreasing MDA serum and TNF- $\alpha$ expression.

Biophytum petersianum; green tea; Cucumis melo; endometriosis; antioxidant herbs Permalink/ DOI: https://doi.org/10.14710/jbtr.v5i2.4716 
(ROS), causes inflammation which is characterised by recruiting lymphocytes and macrophage activation, produces cytokines that induce oxidation enzyme, and supports endothelial growth. ${ }^{5}$ Tumor necrosis factor alpha (TNF- $\alpha$ ) also plays an essential role in the development of endometriosis disease. TNF- $\alpha$ regulates the secretion of inflammatory mediators and invasion of epithelial cells. ${ }^{6,7}$ Besides, the ectopic endometrial tissue, especially peritoneum can survive due to estrogen support and resistance to progesterone, as well as blood supply formed by angiogenesis. Increased ROS in the peritoneum causes an inflammatory reaction that later may pass through surveillance due to immune system dysfunction. Endometriosis implants have anti-apoptotic and pro-proliferative properties that let the lesion grow and spread. ${ }^{5,8}$

Many herbs were examined to be an alternative treatment for endometriosis, because of its high antioxidant capacity. Kebar grass (Biophytum petersianum) is a medicinal plant that has been empirically used by the Papuan to support fertility and relieve menstrual disorders such as irregular cycle and pain. ${ }^{9}$ This herb is the source of phytochemical substances that generally have potent antioxidant activity, and they are believed to play a role in antioxidant defence mechanisms against OS. ${ }^{10}$ Some studies have found that Kebar grass contains alkaloid compounds, steroids, flavonoids, triterpenoids, glycosides, vitamin E, mineral elements and amino acids, which are potential sources of antioxidant. ${ }^{11,12}$ Liquid Chromatography Mass Spectrometry Analysis of the hydro-alcoholic extract revealed Green tea (Camellia sinensis) contains Quercetin glycoside, Epigallocatechin Gallate, Gallo Catechin, Caffeine and Gallic Acid. ${ }^{13}$ The Epigallocatechin Gallate (EGCG) have potential antiangiogenic and anti-oxidation properties to inhibit the growth of endometriosis. ${ }^{14}$ A combination of Cucumis melo extract and wheat gliadin increases endogenous antioxidant levels and also promoted the cellular defences by strengthening the antioxidant status, may also be useful in the treatment of endometriosis. ${ }^{15}$

We are interested in researching three potential antioxidant sources: Kebar grass, green tea and the combination of melon superoxide dismutase and wheat gliadin (Glisodin ${ }^{\circledR}$ ). Kebar grass is one of Indonesia's medicinal plants originally from Papua and traditionally used as fertilising support since a long time ago. It was also believed to treat menstrual disorders such as irregular cycles and menstrual pain. ${ }^{9}$ Kebar extract contains biflavones and flavonoids that may increase the conversion of estradiol to estrone, inhibit aromatization of androgen into estrogen, and induce apoptosis in cancer cells and endometriosis. Kebar grass also contains vitamin $\mathrm{C}$, vitamin $\mathrm{E}$ and other compounds with natural antioxidant activity. ${ }^{11}$ Kebar grass may have an essential role in the reproductive system because of secondary metabolites of flavonoids, namely daidzein and genistein, which are phytohormones that can affect humans and animal reproductive hormones. ${ }^{12}$

\footnotetext{
* Corresponding author:

E-mail: yulitrisetiyono@fk.undip.ac.id

(Yuli Trisetiyono)
}

Green tea has a significant chemical component called EGCG which has been shown high antioxidant capacity and also demonstrated anti-angiogenic potency. It may also represent a promising therapeutic agent in the treatment of endometriosis. ${ }^{16-18}$ The combination of Cucumis melo-gliadin, a commercial pharmaceutical product that contains antioxidant orally available. CMEgliadin combination affects general antioxidant defences, its increase endogenous SOD activity, and prevent cellular damage after induction of oxidative stress. CMEgliadin had some beneficial health aspects on metabolic disorders, cardiovascular diseases, inflammation and cancer, infection, brain function, skin damage and sports nutrition. We thought they could be used as alternative therapies for endometriosis. ${ }^{19}$

This research examined endometriosis mice models fed with Kebar grass extract (KGE), green tea extract (GTE) or Cucumis melo extract and wheat gliadin combination (CME-gliadin) for 14 days, compared with the control group without any treatment. We used mice in this experiment because the existing research on KGE as an alternative therapy for endometriosis is still limited. Mice have reproductive organs similarly to humans with short estrus cycles. Previous research has also proven that mice are easily made into endometriosis models. ${ }^{20}$ It aims to evaluate the potency of KGE, GTE and CME-gliadin to increase the antioxidant defence resulting in a decrease of oxidative stress, inflammation, and angiogenesis; which inhibits endometriotic tissue extension.

\section{MATERIALS AND METHODS}

This research employs experimental study in mice and has acquired ethical approval from the Health Research Ethics Commission of Medical Faculty of Diponegoro University \& Kariadi Hospital (No.56/EC/H/FK-RSDK/VII/2017). The samples were three months old Balb/c female mice weighing 15-20 grams. Twenty-eight mice were involved in the research during the stage of sample calculation and divided into four groups. Each group consisted of seven endometriosis mice models: the first group was given with KGE, the second group received GTE, the third group received CME-gliadin, and the last group was a control without any treatment. Each treatment was given for fourteen days (fig. 1), equivalent to three estrus cycles, considered sufficient to observe the effects of treatments to mice. ${ }^{9}$

We brought dried Kebar grass (all parts from roots to leaves) directly from Kebar District, Manokwari Regency, Papua, while green tea leaves from Medini tea plantations at Kendal Regency. Making ethanol fraction of kebar grass water was done by smoothing it into powder, using a pollinating machine with a $1 \mathrm{~mm}$ filter hole diameter. Five hundred grams of Kebar grass powder was defatted in $5 \mathrm{~L}$ of petroleum ether for $3 \times 1$ hours at room temperature. After filtering petroleum ether, the residue was macerated in methanol (1:5) for 12 hours. The results stored in Erlenmeyer. The maceration process was repeated three times until macerate was obtained from 3 times immersion. The macerate was evaporated to the final result of gel extraction. ${ }^{21}$ On the other hand, tea leaves were cleaned and washed under running tap water, dried and put into a simplicia oven at $50^{\circ} \mathrm{C}$ for $1-2$ days. After drying, green tea leaves powder 
was soaked with methanol solvent (in ratio methanol : plant $=6: 1)$ and left for two days and covered by using aluminum foil to keep from evaporation and resulted in the excellent quality extract. Soaked green tea leaf powder was squeezed using filter paper. Then, methanol was entirely removed by vacuum evaporator at $50^{\circ} \mathrm{C}$ till it gave a viscous extract. ${ }^{22,23}$ Since there was no standard dose of both KGE and GTE available, we used the animal conversion dose and also referring to previous research. We justified $\mathrm{KGE}$ dose $3 \mathrm{mg} / \mathrm{head} /$ day, ${ }^{9,24}$ while GTE dose of $200 \mathrm{mg} / \mathrm{kgBW} /$ day. ${ }^{24,25} \mathrm{CME}$-gliadin was taken from Glisodin $\AA$ capsules (Kalbe Farma, PT $\mathrm{TbK}$ ), with the dose $5 \mathrm{IU} /$ day equal to $5 \mathrm{mg} /$ day. ${ }^{24,26}$ $\mathrm{ml}$ cyclosporine-A i.m and $5.4 \mu \mathrm{g} 17 \beta$-estradiol i.m on day 1 and day $5 .{ }^{27,28}$

Starting from day 14 until day 28, the first group received $3 \mathrm{mg} /$ day $\mathrm{KGE}$, second group received 200 $\mathrm{mg} / \mathrm{kgBw} /$ day GTE, third group received $5 \mathrm{mg} /$ day (equal to 5IU/day) CME-gliadin, whereas the control group received daily feed only. All of the mice were sacrificed on day 28 , using ketamine $100 \mathrm{mg} / \mathrm{kgBW}$, while taking blood samples from their hearts for malondialdehyde (MDA) serum examination by spectrophotometry. Mice were killed by cervical dislocation, followed by opening the peritoneal cavity to measure the area of endometriosis implants by tracing computerised with Motic Image ${ }^{\circledR}$

\section{Enrollment}

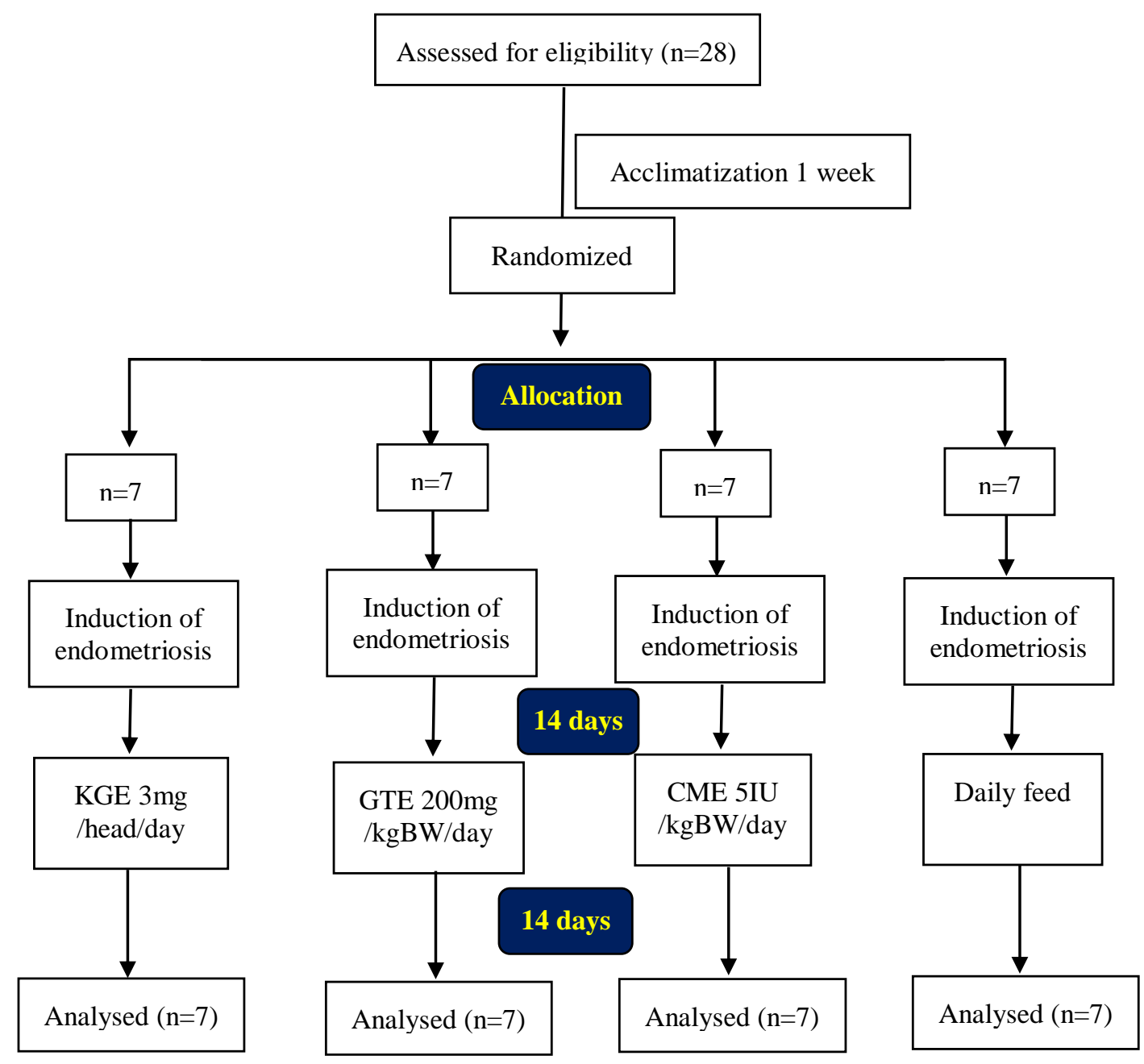

Figure 1. Flow diagram of the study

We developed the endometriosis model mice based on previous research, which uses heterologous techniques with a success rate of $95.7 \% .{ }^{27}$ Human endometrial tissues were obtained from women who underwent hysterectomy for benign uterine diseases, washed twice with phosphate-buffered saline (PBS) and mixed as crude fragments in PBS with penicillin 200 $\mathrm{IU} / \mathrm{ml}$ and streptomycin $200 \mu \mathrm{g} / \mathrm{ml}$. Endometrial tissues solution of $0.1 \mathrm{ml}$ was injected intraperitoneally using $16 \mathrm{G}$ needle to each mouse, followed by injection of 0.2 software (fig. 2). Then, peritoneum with endometriotic implants was sent to the laboratory for immunohistochemical examination of Tumor Necrosis Factor Alpha (TNF- $\alpha$ ) and Vascular Endothelial Growth Factor (VEGF) expression referring to the Rammele Scale Index (ImmunoReactive Score). ${ }^{29}$ All obtained data were analysed statistically using SPSS, and significance was determined by $\mathrm{p}<0.05$. 


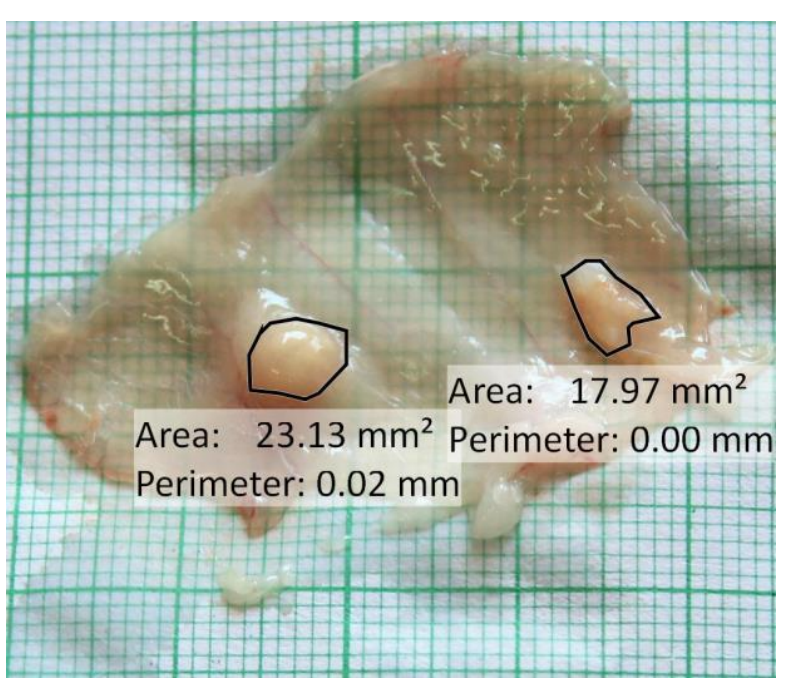

Figure 2. Endometriotic implants in mice peritoneum and how to measure the area by computerize tracing.

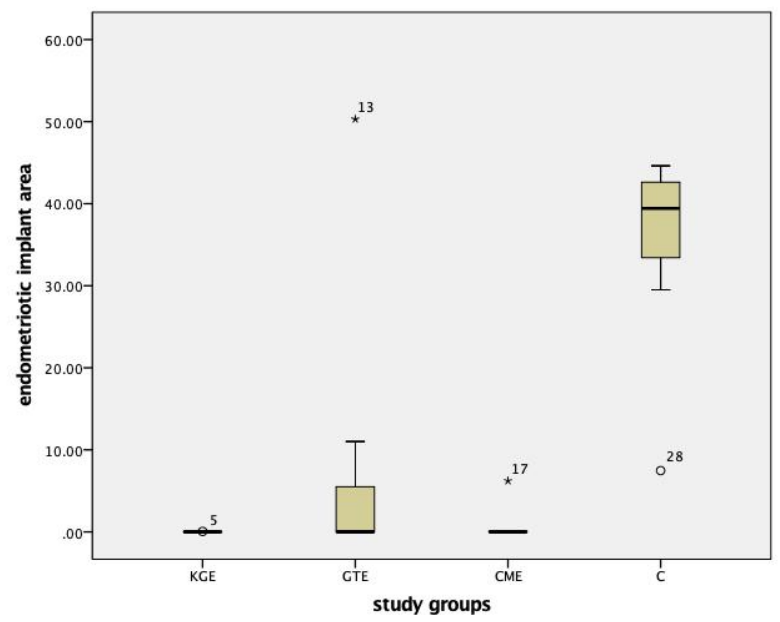

Figure 3. The area of the endometriotic implants in the mice peritoneum. The Kruskal-Wallis statistical test and found $\mathrm{p}=0.003$. In comparison among groups, a post hoc test Mann-Whitney obtained means of endometriotic implants area : KGE vs GTE $\mathrm{p}=0.102$, KGE vs CMEgliadin $\mathrm{p}=0.780, \mathrm{KGE}$ vs control $\mathrm{p}=0.003$, GTE vs CME-gliadin $\mathrm{p}=0.941$, GTE vs control $\mathrm{p}=0.006$, and CME-gliadin vs control $\mathrm{p}=0.002$.

\section{RESULTS}

On the twenty-eighth day, all mice from all treatment groups $(28$ mice) were still alive and included for examination and data analysis.

\section{Endometriotic implants area}

After mice were turned off, the peritoneal cavity were opened to find out endometriosis implants. Lesions in the form of granuloma tissue, may stick and spread throughout the abdominal cavity. The means of endometriotic implants area in peritoneal tissue of the mice in KGE group, GTE group, CME-gliadin group and the control group were $0.01 \pm 0.025 \mathrm{~mm} 2,8.76 \pm 18.776$ $\mathrm{mm} 2,0.91 \pm 2.346 \mathrm{~mm} 2$, and $34.80 \pm 13.079 \mathrm{~mm} 2$, respectively. (fig. 3) The normality test showed data distribution of endometriosis implants area was not normal, so we used the non-parametric Kruskal-Wallis statistical test and found a significant difference among the study groups $(\mathrm{p}=0.003)$. In comparison among groups, a post hoc test Mann-Whitney obtained means of endometriotic implants area in all treatment groups were significantly smaller compared to the control group ( $\mathrm{p}=$ $0.003,0.006$, and 0.002).

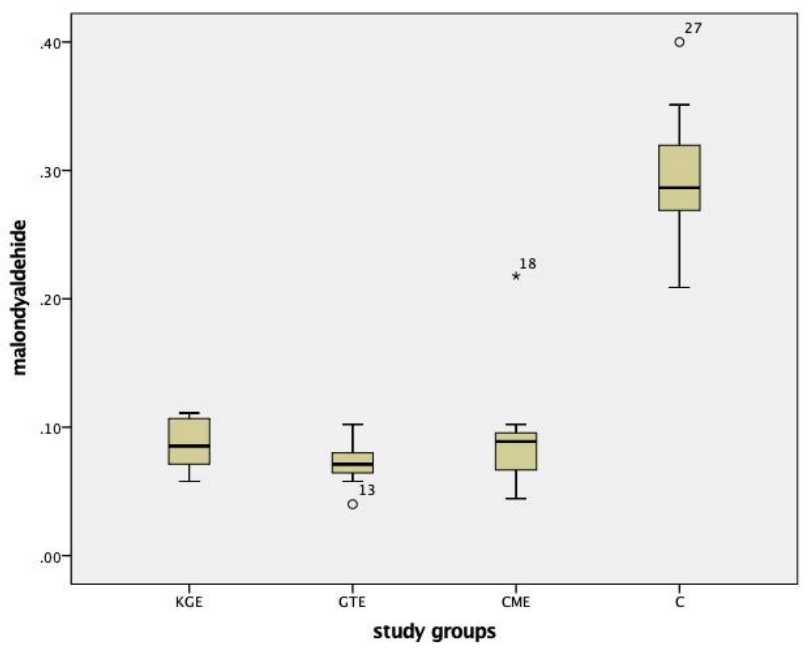

Figure 4. MDA levels of endometriosis mouse models. The Kruskal-Wallis statistical test showed $\mathrm{p}=0.001$. The post hoc test Mann-Whitney obtained means of MDA serum levels: KGE vs GTE $\mathrm{p}=0.124$, KGE vs CMEgliadin $\mathrm{p}=0.337$, KGE vs control $\mathrm{p}=0.001$, GTE vs CMEgliadin $\mathrm{p}=0.367$, GTE vs control $\mathrm{p}=0.001$, and CMEgliadin vs control $\mathrm{p}=0.003$.

\section{MDA serum level}

The means of MDA serum levels in KGE group, GTE group, CME-gliadin group and the control group were $0.09 \pm 0.022 \mathrm{mmol}, 0.07 \pm 0.019 \mathrm{mmol}, 0.10 \pm 0.057 \mathrm{mmol}$, and $0.30 \pm 0.062 \mathrm{mmol}$; respectively. (fig. 4) The KruskalWallis statistical test showed a significant difference among the study groups ( $\mathrm{p}=0.001)$. In comparison among groups, a post hoc test Mann-Whitney obtained means of MDA serum levels of the mice in all treatment groups were significantly different compared to control group ( $p$ $=0.001,0.001$, and 0.003).

\section{TNF- $\alpha$ expression}

Immunohistochemical staining of peritoneal tissue in fig. 5 showed the highest intensity of TNF- $\alpha$ expression has appeared in the control group. The means of TNF- $\alpha$ expression in peritoneal tissue of endometriosis mice of KGE group, GTE group, CME-gliadin group and the control group were $2.43 \pm 1.521,3.66 \pm 1.422,2.63 \pm 1.029$, and 7.26 \pm 2.898 , respectively. (fig. 6) The Kruskal-Wallis statistical test showed a significant difference among the study groups $(\mathrm{p}=0.002)$. In comparison among groups, a post hoc test Mann-Whitney obtained means of TNF- $\alpha$ expression in all treatment groups were significantly different compared to control group ( $\mathrm{p}=0.002,0.002$, and 0.002).

\section{VEGF expression}

Immunohistochemical staining of peritoneal tissue in fig. 7 showed the lowest intensity of VEGF expression has appeared in the CME-gliadin group. The means of VEGF expression on peritoneal tissue of endometriosis mice of KGE group, GTE group, CME-gliadin group and 
the control group were 4.34 $\pm 2.402,4.57 \pm 1.998$, $1.63 \pm 0.678$, and $7.40 \pm 3.495$, respectively. (fig. 8) The ANOVA statistical test has been used due to normal data distribution and found a significant difference among the study groups $(\mathrm{p}=0.002)$. However, the Games-Howell post hoc test showed only CME-gliadin group had significantly lower compared to the control group $(\mathrm{p}=0.017)$.
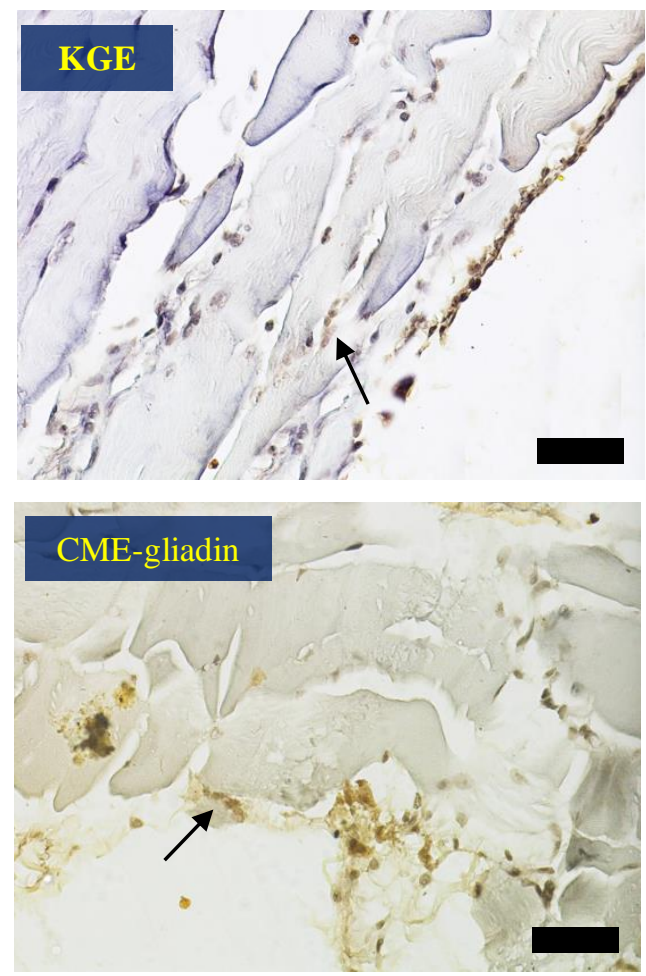

endometriosis implants than the control group. ${ }^{35}$ Furthermore, Kebar grass extract also contains a high concentration of daidzein phytohormones may decrease the risk of advanced stage endometriosis by interacting with estrogen receptor two gene polymorphism. ${ }^{36}$ Green tea catechins and procyanidins have anti-oxidant activity. In a previous study, ECG and EGCG showed better antioxidant activity on lipid peroxidation. ${ }^{14}$ In some
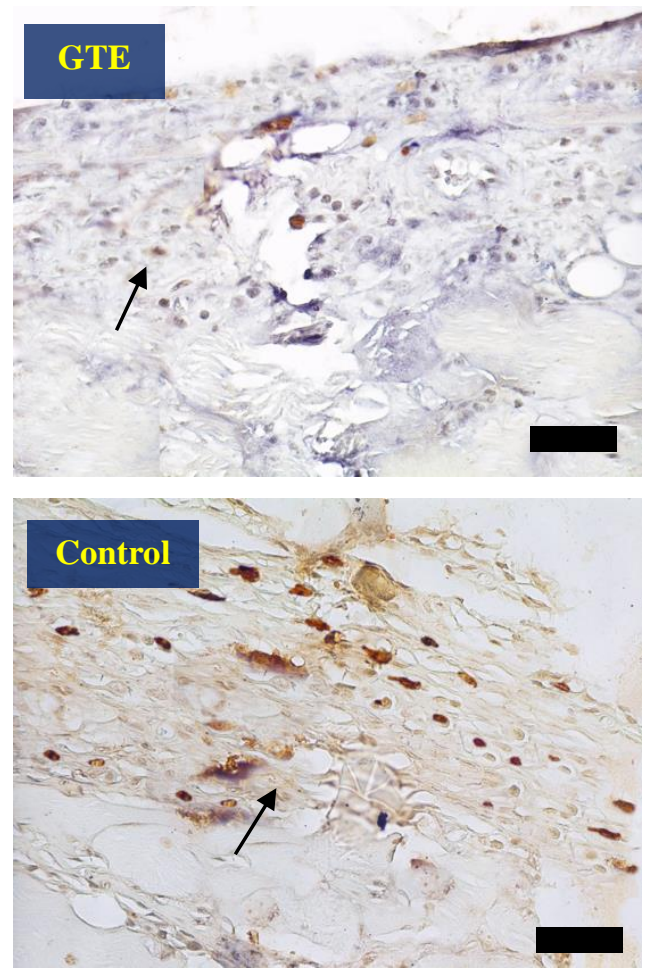

Figure 5. Histochemical immunostaining of TNF- $\alpha$ expression among study groups. The expression of TNF- $\alpha$ in granulation tissue is indicated by chromogen brown color (arrow). The highest intensity appeared in the control group (Nikon H600L microscope; 300 megapixel DS camera; black bar: 10 $\mu \mathrm{m}$ ).

\section{DISCUSSION}

Currently, various studies have shown the role of oxidative stress and antioxidants in the pathogenesis of endometriosis. ${ }^{30}$ That has led many recent studies tried to investigate the role of antioxidants in the treatment of endometriosis.

Our research has revealed that each administration of KGE, GTE and CME-gliadin reduced endometriotic tissue implants on mice peritoneum, compared with the control group. Ethanol extract of KGE contains phenolic compounds such as tannins, phenolics, and flavonoids. It is also known to contain vitamin $\mathrm{E}$, vitamin $\mathrm{C}$, folic acid, hecadecanoic acid, 9.17-octadadenal, ergost-5-en3-ol, stigmast-5-en-3-ol, which can be used as a source of antioxidants. ${ }^{11,30-32}$ Then we suspect that KGE as well as both GTE and CME-gliadin have components with potential antioxidants, decrease oxidative stress occurring in the pathogenesis of endometriosis disease. ${ }^{14,19,33}$ A previous study has shown supplementation of the combination of vitamin E 1200 IU and vitamin C $1000 \mathrm{mg}$ daily to endometriosis patients for eight weeks reduced the level of pelvic pain. ${ }^{34}$ Another study given vitamin C $500 \mathrm{mg} / \mathrm{kg}$ every two days intravenously to endometriosis model mice found a significantly smaller proportion of researches, GTE with high antioxidant capacity has a good effect in the treatment of some tumors by involved in cell mutation, proliferation, invasion and apoptosis. In 14 days administration of EGCG to isolated hamster endometrial stromal cells and glandular cells in vitro, EGCG suppresses E2-stimulated activation and proliferation of endometrial cells and induces regression of the endometriotic lesions. ${ }^{18}$ Although we found no research on CME-gliadin for endometriosis, we assume CME-gliadin should play a role in the treatment of endometriosis because of its high antioxidant capacity. Several studies on animals also clinical trials using healthy volunteers confirmed the preservation of the antioxidant activity of the SOD enzyme after oral administration; combined with anti-inflammatory and immunomodulatory properties. ${ }^{37}$

Finding out the role of each treatment in inhibiting the expansion of endometriosis implants in mice peritoneum, we examined several biomarkers, i.e. MDA serum level, TNF- $\alpha$ and VEGF expression on endometriotic implants. Administration of antioxidant herbs could reduce the expansion of endometriosis lesions through several pathways. They will increase antioxidant capacity, reduce oxidative stress which is marked by the decline in MDA biomarkers. Supression on oxidative stress directly 
reduce angiogenesis in endometriosis as indicated by a decrease in VEGF biomarkers. Indirectly reduces inflammation by decreasing TNF- $\alpha$, thereby reducing endothelial damage and adhesion to the disease. . $, 3,6,8^{-}$

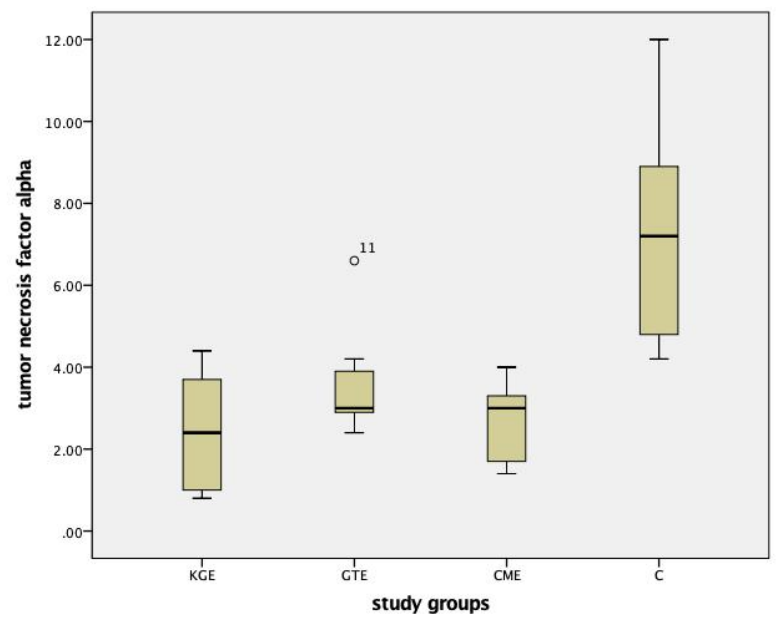

Figure 6. TNF- $\alpha$ expression of peritoneal endometriotic tissue. The Kruskal-Wallis statistical test showed $p=0.002$. The post hoc test Mann-Whitney obtained means of TNF- $\alpha$ expression: KGE vs GTE $\mathrm{p}=0.275$, KGE vs CME-gliadin $\mathrm{p}=0.411$, KGE vs control p=0.002, GTE vs CME-gliadin $\mathrm{p}=0.244$, GTE vs control $\mathrm{p}=0.002$, and CME-gliadin vs control $\mathrm{p}=0.002$.
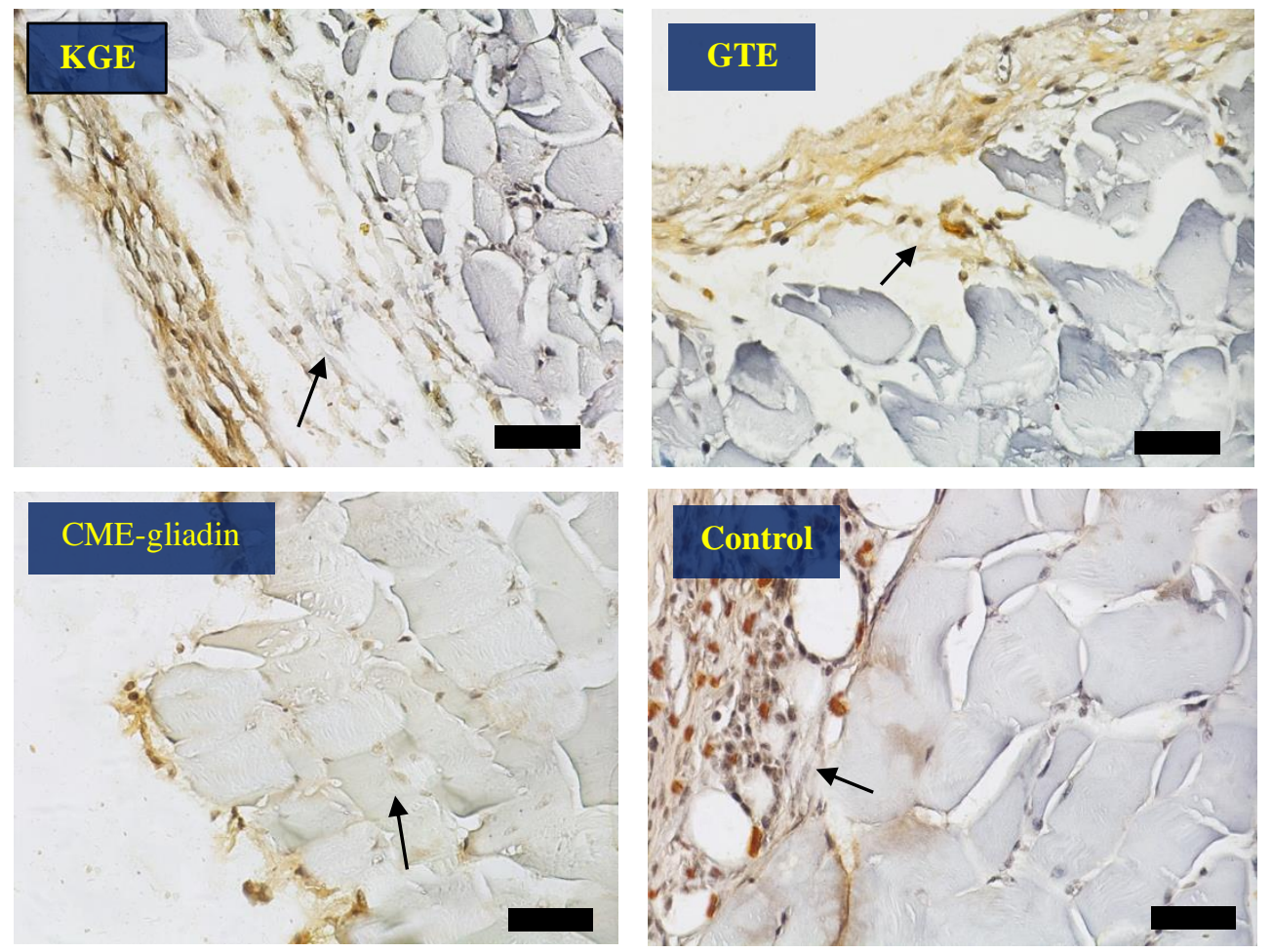

Figure 7. Histochemical immunostaining of VEGF expression among study groups. The expression of VEGF in granulation tissue is indicated by chromogen brown color (arrow). The lowest intensity appeared in the CMEgliadin group (Nikon H600L microscope; 300 megapixel DS camera; black bar: 10 $\mathrm{m}$ )

Because of this reason, we tried to examine MDA as a biomarker of OS. We found KGE, GTE and CME- gliadin decreased MDA level in mice blood serum. The possibility that antioxidant capacity in all three treatments would strengthen the performance of endogenous antioxidant defences against OS, resulting in reduced MDA as an OS product. The results are relevant to another study provided curcumin $24 \mathrm{mg}$ /day for 14 days supplementation as an antioxidant to the mice model of endometriosis and found lower ovarian MDA titer than the control group. ${ }^{20}$ The previous study administered various doses of green tea catechin to $\mathrm{Pb}$-induced oxidative stressed mice. They found $22.5 \mathrm{mg} / \mathrm{kg} / \mathrm{day}$ green tea leaves modulate oxidative stress in $\mathrm{Pb}$-exposed erythrocytes by decreasing MDA and increasing SOD enzyme activity. ${ }^{23}$ In a double-blind experimental with pre-post test and control group, two capsules GTE supplementation for 30 days to fifty-seven elder people has decreased MDA significantly. ${ }^{38}$ An experimental study gave three doses of CME-gliadin to rats exposed by cigarette smoke for 28 days, they found that the higher the dosage of CME-gliadin resulted in lower MDA serum level. ${ }^{26}$

Endometriosis is a condition often associated with inflammation. Many studies had revealed some cytokines and chemokines which were emerging as key players in endometriosis pathobiology, TNF- $\alpha$ is one of the increasing inflammatory cytokines in endometriosis. ${ }^{39}$ TNF- $\alpha$ is a local proinflammatory mediator will activate nuclear factor $\kappa \mathrm{B}(\mathrm{NF}-\kappa \mathrm{B})$, and hypoxia-inducible factor (HIF)- $1 \chi$ signalling pathways, and then increase cyclooxygenase (COX)-2 expression in endometriosis. ${ }^{40}$

In our study, KGE, GTE and CME-gliadin administration to mice resulted in lower TNF- $\alpha$ expression in endometriotic tissue. Vitamin $\mathrm{C}$ and vitamin $\mathrm{E}$ in Kebar 
grass extract should act as a potent anti-inflammatory to decrease biomarkers like TNF- $\alpha$. These results corresponded with another study administered a combination of vitamin E $1000 \mathrm{mg} /$ day and vitamin C $1000 \mathrm{IU} /$ day for four weeks to the elderly who had fasting glucose disorder. They found decreased levels of isoprostane-8 and TNF- $\alpha .^{41}$ Inflammation is a pathophysiological manifestation of numerous diseases including tumors. Pro-inflammatory signals such as TNF- $\alpha$ and IL-1, carcinogens, a tumor promoter, and lipid mediators stimulate $\mathrm{COX}-2$ transcription via several pathways. It let two main arachidonic acid regulatory pathways, the $\mathrm{NF}-\kappa \mathrm{B}$ regulation of $\mathrm{COX}-2$ transcription and the mitogen-activated protein kinase (MAPK) pathway. ${ }^{42}$ Inhibition of COX-2 is one of the many proposed mechanisms by which dietary phytochemicals including EGCG as the major biologically active polyphenolic flavan-3-ols flavonoid constituent in GTE, may prevent tumor growth. GTE attenuates lipid peroxidation and PGE2 accumulation by decreasing COX-2 activity, and decreases the protein and mRNA expression levels of COX-2 and the mRNA expression of inflammatory cytokines: TNF- $\alpha$, IFN- $\gamma$, IL-6, IL-12, and IL-18. ${ }^{42}$ This catechins enhanced cancer preventive activities, such as induction of apoptosis, and inhibition of cell growth and TNF- $\alpha$ which acts as an endogenous tumor promoter. ${ }^{43,44}$ Similarly, green tea polyphenols are potent antioxidants with important roles in regulating vital signalling pathways in chronic inflammatory disease include endometriosis. EGCG in GTE can block the activation of the NF- $\kappa B$ and the release of proinflammatory TNF- $\alpha$ in intestinal epithelia. The green tea polyphenols were able to inhibit NF- $\kappa \mathrm{B}$ activation and release of TNF- $\alpha$ can be responsible for the anti-inflammatory effects of green tea consumption. ${ }^{45,46}$ Twenty-eight days supplementation of Cucumis melo LC. extract rich in superoxide dismutase activity combined with wheat gliadin to C57BL/6 mice followed by injection of the pro-inflammatory cytokine IFN- $\gamma(300 \mathrm{IU})$ intra-peritoneal regulated the activation state of macrophages as indicated by their decreased production of the pro-inflammatory cytokine TNF- $\alpha$ and by their promoted production of the anti-inflammatory cytokine IL-10. ${ }^{47}$

The role of angiogenesis in the pathophysiology of endometriosis is indisputable. Indeed, endometriotic cells require an adequate blood supply to survive in their ectopic sites. Endometriotic lesions are typically characterised by a dense vascularisation that occurs through the angiogenesis process. Endometriotic lesions can produce cytokines and growth factors that regulate their proliferation and vascularisation. IL- $1 \beta$, the dominant IL-1 secreted by activated peritoneal macrophages, plays an important role in the neovascularization of endometriotic lesions. ${ }^{4}$ VEGF is the most prominent and the most studied of angiogenic growth factors have been identified, which are expressed in endometriotic lesions and released into the peritoneal fluid of patients with endometriosis, which acts as a potent, selective endothelial mitogen and survival factor. Interestingly, highly active red endometriotic lesions contain the highest concentration of VEGF, and the concentration of VEGF peritoneal fluid correlates with the stage of endometriosis. ${ }^{48}$ Unfortunately, present study results showed KGE and GTE administration insignificantly decreased VEGF expression in the endometriotic tissues from mice peritoneum. Whereas a previous study has shown that flavonoids and vitamin $\mathrm{E}$ can reduce VEGF expression in-vitro. ${ }^{49}$ Another study used phyto-pharmacy containing isoflavone genistein for six months to endometrial hyperplasia patients and found a significant reduction of VEGF, EGF and TGFB expressions. ${ }^{50}$ Similarly, other study of herbal medicine found that isoflavone may be anti-estrogenic and able to reduce VEGF level in endometrial cell culture. The higher dose of isoflavone and longer incubation tend to decrease the VEGF-A level. ${ }^{51}$ Some previous study examined the benefits of GTE for endometriosis shown that green tea catechins especially EGCG have antiangiogenic effects to microvascular endothelium and suppressed the growth and survival of experimental endometriosis in severely compromised immunodeficient mice. Mouse VEGFA mRNA expression in lesions with EGCG treatment was significantly down-regulated and decreased. ${ }^{16}$ A study analysed the effect of EGCG on the eutopic endometrium, treated endometriosis model mice with 65 $\mathrm{mg} / \mathrm{kg}$ EGCG daily for three days. Their study resulted in EGCG inhibits E2-induced activation, proliferation and VEGF expression of endometrial cells. ${ }^{18}$ Further research is needed by carrying various doses of KGE and GTE, and examining other angiogenesis markers. In the other hand, CME-gliadin administration to mice resulted in a significant reduction of VEGF expression in endometriotic tissue. In endometriosis implants occur recruitment of new capillaries from adjacent micro peritoneal vessels, however, vasculogenesis, i.e. new blood vessel derived from circulating endothelial progenitor cells (EPC), also take place in the pathogenesis of endometriosis. The endometrium is a dynamic tissue that shows the population of epithelial stem cells and clonogenic stroma require active angiogenesis. EPC originating from the bone marrow can be detected in proliferating endometriotic lesions, and these lesions show an increase of factor and chemokine expression participating in EPC recruitment, such as hypoxia-inducible-factor-(HIF-) $1 \alpha$ and stromal-cellderived-factor-(SDF-)1. Therefore, the presence of hypoxia, endothelial injury, inflammation and expression of ER- $\alpha$ contribute to mobilisation and recruitment of EPC from the bone marrow to endometriotic implants. ${ }^{4,52}$ The antioxidant activity of SOD presents in Cucumis melo extract develop new classes of nutrition supplements that could reduce the biological disorders induced by various pro-inflammatory and oxidative stress mechanisms. It will increase endogenous antioxidant defences, scavenge oxidative stress due to hypoxia, reduce endothelial damage, and improve inflammatory reactions, then prevent of recruitment of EPC for vasculogenesis, result in inhibition of endometriosis proliferation. ${ }^{19,47}$ Interestingly, in an invivo study, the researcher added Cucumis melo extract to stem cell culture. During the culture, stem cells differentiate due to growth factors existed in culture media, which direct stem cells into EPCs. Addition of Cucumis melo has a positive effect of reducing the level of ROS. This treatment also improved the function of $\mathrm{EPC}$ in forming the structure of angiogenesis, which 
resulted in a better tube formation structure. ${ }^{53}$ From our study results, we assumed that CME extract modulates the function of vasculogenesis and angiogenesis in endometriosis tissue.

The limitations of this study is that not test using various doses of each therapy. We did not use a combination of each therapy, so it did not answer whether combining these therapies would provide better results. However, the overall results of this study show that these medicinal herbs has a good effect on endometriosis disease. Thus, further investigation is needed to be conducted to consider them may be used as an alternative therapy for endometriosis.

\section{CONCLUSION}

Kebar grass extract, green tea extract and CMEgliadin administration reduce endometriotic implant area in mouse models of endometriosis by decreasing MDA serum level and TNF- $\alpha$ expression of peritoneal endometriotic tissue, although only CME-gliadin also reduces VEGF expression.

\section{ACKNOWLEDGEMENTS}

The authors would like to acknowledge the excellent and efficient teaching staff of reproductive endocrinology and infertility subspecialist education of Diponegoro University/Kariadi Hospital, laboratory staff of pharmacy faculty of Diponegoro University, and also laboratory staff of the veterinary faculty of Airlangga University.

\section{REFERENCES}

1. Fritz MA, Speroff L. Endometriosis. In: Clinical gynecologic endocrinology and infertility. 8th ed. Philadelphia: Lippincott Williams \& Wilkins; 2011. p. 1221-48.

2. Sekhon LH, Agarwal A. Endometriosis and oxidative stress. In: Agarwal A, Aziz N, Rizk B, editors. Studies on women's health. New York: Humana Press; 2013. p. 149-67.

3. Kralickova M, Vetvicka V. Role of angiogenesis in endometriosis. Pathol Discov. 2016;4(1):1-5.

4. Rocha ALL, Reis FM, Taylor RN. Angiogenesis and endometriosis. Obstet Gynecol Int. 2013;2013:1-8.

5. Sourial S, Tempest N, Hapangama DK. Theories on the pathogenesis of endometriosis. Int $\mathrm{J}$ Reprod Med. 2014;2014:1-9.

6. Grund EM, Kagan D, Tran CA, Zeitvogel A, Starzinski-Powitz A, Nataraja $S$, et al. Tumor necrosis factor-a regulates inflammatory and mesenchymal responses via mitogen-activated protein kinase, p38, and nuclear factor B in human endometriotic epithelial cells. Mol Pharmacol. 2008;73:1394-404.

7. Sanchez G, Zubor P, Szunyogh N, Kajo K, Machalekova $\mathrm{K}$, Biringer $\mathrm{K}$, et al. [TNF-alpha serum levels in women with endometriosis: prospective clinical study]. Ces Gynekol. 2005;70(4):286-90.

8. Harada $\mathrm{T}$, Taniguchi $\mathrm{F}$, Izawa M, Ohama Y, Takenaka Y, Tagashira Y, et al. Apoptosis and endometriosis. Front Biosci. 2007;12:3140-51.
9. Sadsoeitoeboen PD. [Benefits of Kebar Grass extract (Biophytum petersianum Klotzsch) on the reproductive appearance of white female mice]. Institut Pertanian Bogor; 2005. 1-45 p.

10. Alok S, Jain SK, Verma A, Kumar M, Mahor A, Sabharwal M. Herbal antioxidant in clinical practice: a review. Asian Pac J Trop Biomed. 2014;4(1):7884.

11. Sembiring B, Darwati I. [Identification of chemical components of accession of Kebar Grass (Biophytum petersianum) from Papua and Java]. Obat BPTR dan, editor. 2014;25(1):37-44.

12. Sukarsono. [Profile of secondary metabolite content of medicinal plants Biophytum petersianum and Biophytum sensitivum]. J Gamma. 2012;6(1):6976.

13. Thakur P, Chawla R, Narula A, Goel R, Arora R, Sharma RK. Assessment of aquo-ethanolic extract of Camellia sinensis against Carbapenem Resistant Escherichia coli: In Vivo Trials in a Murine Model. Biomed Pharmacother. 2016;79:273-83.

14. Man GCW, Xu H, Wang CC. Green Tea for Endometriosis. Chaudhury K, Chakravarty B, editors. Endometriosis. IntechOpen; 2012.

15. Romao $\mathrm{S}$. Therapeutic value of oral supplementation with melonsuperoxide dismutase and wheat gliadin combination. Nutrition. 2015;31(3):430-6.

16. Xu H, Lui WT, Chu CY, Ng PS, Wang CC, Rogers MS. Anti-angiogenic effects of green tea catechin on an experimental endometriosis mouse model. Hum Reprod. 2009;24(3):608-18.

17. Xu H, Becker CM, Lui WT, Chu CY, Davis TN, Kung AL, et al. Green tea epigallocatechin-3-gallate inhibits angiogenesis and suppresses vascular endothelial growth factor $\mathrm{C} /$ vascular endothelial growth factor receptor 2 expression and signaling in experimental endometriosis in vivo. Fertil Steril. 2011;96(4):1021-8.

18. Laschke MW, Schwender C, Scheuer C, Vollmar B, Menger MD. Epigallocatechin-3-gallate inhibits estrogen-induced activation of endometrial cells in vitro and causes regression of endometriotic lesions in vivo. Hum Reprod. 2008;23(1):2308-18.

19. Romao $S$. Therapeutic value of oral supplementation with melon superoxide dismutase and wheat gliadin combination. Nutrition. 2015;31(3):430-6.

20. Panjaitan BC, Sa'adi A, Hendarto H, Widjiati. Comparison of ovarial malondialdehyde (MDA) level between endometriosis rat given with and without curcumine supplementation. Maj Obstet Ginekol. 2012;20(1):30-4.

21. Tethool AN, Sambodo P. [Effect of ethanol fraction of Kebar grass water (Biophytum petersianum Klotzsch) on leukocyte differentiation of hyperlipidemic rabbits]. Agrinimal. 2015;5(1):31-6.

22. Prabha LS, Venkatachalapathi T, Venkatesan RS. Phytochemical analysis of Greentea ( Camellia sinensis ) and assessment of its scavenging ability on $\mathrm{CdCl}$ 2. Int $\mathbf{J}$ Curr Res Chem Pharm Sci. 2016;3(8):47-57.

23. Sukina B, Prabowo GI, Suhartati S, Harianto N. [Green tea catechins (Camellia sinensis) against malondialdehyde and superoxide dismutase]. Indones J Clin Pathol Med Lab. 2013;19(2):92-7. 
24. Nair AB, Jacob S. A simple practice guide for dose conversion between animals and human. $\mathrm{J}$ basic Clin Pharm. 2016;7(2):27-31.

25. Himawan R. [Effect of green tea leaf extract (Camellia sinensis) on levels of isoniazid-induced white rats (Rattus novergicus)]. Universitas Sebelas Maret. Universitas Sebelas Maret; 2008.

26. Suryadinata RV, Wirjatmadi B, Adriani M. Effectiveness decrease combined with supplements malondialdehyde antioxidant superoxide dismutase gliadin melon with due to exposure to cigarette. Glob Med Heal Commun. 2017;5(2):79-83.

27. Awwad JT, Sayegh RA, Tao XJ, Hassan T, Awwad ST, Isaacson K. The SCID mouse: an experimental model for endometriosis. Hum Reprod [Internet]. 1999;14(12):3107-11. Available from: https://www.ncbi.nlm.nih.gov/pubmed/10601104

28. Hendarto H, Widjiati, Johari S. [Curcumin supplementation to improve oocyte maturation and results of in vitro fertilization in endometriosis mice]. Maj Obstet Ginekol. 2014;22(2):53-7.

29. Nowak M, Madej JA, Dziegiel P. Intensity of cox2 expression in cells of soft tissue fibrosacrcomas in dogs as related to grade of tumour malignancy. Bull Vet Inst Pulawy. 2007;51:275-9.

30. Gupta S, Chandra A, Kesavan S, Eapen D, Agarwal A. Oxidative Stress and the Pathogenesis of Endometriosis. In: Garcia-Velasco JA, Rizk BRMB, editors. Endometriosis: Current management and future trends. Cleveland: ClevelandClinic; 2010. p. 31-9.

31. Jackson LW, Schisterman EF, Dey-Rao R, Browne R, Armstrong D. Oxidative Stress and Endometrosis. Hum Reprod. 2005;20(7):2014-20.

32. Agarwal A, Gupta S, Agarwal A, Krajcir N, Alvarez JG. Role of oxidative stress in endometriosis. Reprod Biomed Online. 2006;13(1):126-34.

33. Das K, Bhattacharyya J. Antioxidant Functions of Green and Black Tea. In: Preedy VR, editor. Tea in Health and Disease Prevention. London: Elsevier; 2013. p. 521-8.

34. Santanam N, Kavtaradze N, Murphy A, Dominguez C, Parthasarathy S. Antioxidant supplementation reduces Eendometriosis related pelvic pain in humans. Transl Res J Lab Clin Med. 2014;161(3):189-95.

35. Erten OU, Ensari T gba A, Dilbaz B, Cakiroglu H, Altinbas SK, Çaydere M, et al. Vitamin C is effective for the prevention and regression of endometriotic implants in an experimentally induced rat model of endometriosis. Taiwan $\mathbf{J}$ Obstet Gynecol. 2016;55:251-7.

36. Tsuchiya M, Miura T, Hanaoka T, Iwasaki M, Sasaki H, Tanaka T, et al. Effect of soy isoflavones on endometriosis: interaction with estrogen receptor 2 gene polymorphism. Epidemiology. 2007;18(3):402-8.

37. Menvielle-Bourg FJ. Superoxide dismutase (SOD), a powerful antioxidant, is now available orally. Phytothérapie. 2005;3:1-4.

38. Artika FN, Susetyowati, Pramantara IDP, Lestari LA. [Effect of green tea extract (Camellia sinensis) to plasma malondialdehyde (MDA) level and hand grip strength of elderly]. 2016;13(2):59-66.
39. Greene AD, Lang SA, Kendziorski JA, Sroga-rios JM, Herzog TJ, Burns KA. Endometriosis : Where are We and Where are We Going ? 2017;152(3):129.

40. Wu M-H, Tsai S-J. Endometriosis and possible inflammation markers. Gynecol Minim Invasive Ther. 2015;4(3):61-7.

41. Rizzo MR, Abbatecola AM, Barbieri M, Vietri MT, Cioffi M, Grella R, et al. Evidence for antiinflammatory effects of combined administration of vitamin $\mathrm{E}$ and $\mathrm{C}$ in older persons with impaired fasting glucose: impact on insulin action. J Am Coll Nutr. 2008;27(4):505-11.

42. Desai SJ, Prickril B, Rasooly A. Mechanisms of phytonutrient modulation of Cyclooxygenase-2 (COX-2) and inflammation related to cancer. Nutr Cancer. 2018;70(3):350-75.

43. Suganuma M, Takahashi A, Watanabe T, Iida K, Matsuzaki T, Yoshikawa HY, et al. Biophysical approach to mechanisms of cancer prevention and treatment with green tea catechins. Molecules. 2016;21(11):1-17.

44. Chen Z, Lin Z. Tea and human health: biomedical functions of tea active components and current issues. J Zhejiang Univ B. 2015;16(2):87-102.

45. Helieh SO. Chronic Inflammatory Diseases and Green Tea Polyphenols. Nutrients. 2017;9(6):561.

46. Lin Y-H, Chen Y-H, Chang H-Y, Au H-K, Tzeng C$\mathrm{R}$, Huang $\mathrm{Y}-\mathrm{H}$. Chronic Niche Inflammation in Endometriosis-Associated Infertility: Current Understanding and Future Therapeutic Strategies. Int J Mol Sci. 2018;19(8):2385.

47. Vouldoukis I, Lacan D, Kamate C, Coste P, Calenda A, Mazier D, et al. Antioxidant and antiinflammatory properties of a Cucumis melo LC. extract rich in superoxide dismutase activity. J Ethnopharmacol. 2004;94(1):67-75.

48. Laschke MW, Menger MD. Anti-angiogenic treatment strategies for the therapy of endometriosis. Hum Reprod Update. 2012;18(6):682-702.

49. Schindler R, Mentlein $\dagger$ R. Flavonoids and Vitamin E Reduce the Release of the Angiogenic Peptide Vascular Endothelial Growth Factor from Human Tumor Cells. Journals Nutr. 2006;136:1477-2006.

50. Granese R, Bitto A, Polito F, Triolo O, Giordano D, Santamaria A, et al. Genistein reduces angiogenesis and apoptosis in women with endometrial hyperplasia. Bot Targets Ther. 2014;5(5):27-32.

51. Jehanara, Sutrisno, Santoso S. [Effect of Genistein on Decreasing Vascular Levels of Endothelial Growth Factor-A in Endometriosis Cell Culture]. Maj Obstet Ginekol. 2014;22(2):94-100.

52. Krikun G. Endometriosis, Angiogenesis and Tissue Factor. Scientifica (Cairo). 2012;2012:1-10.

53. Lizandi AO, Sardjono CT, Widowati W, Gunanegara RF, Sandra F. [GliSODin Increases Stem Cells Potency]. Cermin Dunia Kedokt. 2010;37(2):107-10. 